Case Report

\title{
Fatal Aortic Dissection in a Patient with Giant Cell Arteritis: A Case Report and Review of the Literature
}

\author{
Anjeli K. Nayar, ${ }^{1}$ Michael Casciello, ${ }^{2}$ Jennifer N. Slim, ${ }^{3}$ and Ahmad M. Slim ${ }^{1}$ \\ ${ }^{1}$ Department of Cardiology, San Antonio Military Medical Center, San Antonio, TX 78234, USA \\ ${ }^{2}$ Sentara Cardiology, Williamsburg, VA 23188, USA \\ ${ }^{3}$ Department of Medicine, San Antonio Military Medical Center, San Antonio, TX 78234, USA
}

Correspondence should be addressed to Jennifer N. Slim; jennifer.slim@us.army.mil

Received 11 January 2013; Accepted 30 January 2013

Academic Editors: N. Espinola-Zavaleta, L. Masotti, and G. L. Tripepi

Copyright (C) 2013 Anjeli K. Nayar et al. This is an open access article distributed under the Creative Commons Attribution License, which permits unrestricted use, distribution, and reproduction in any medium, provided the original work is properly cited.

\begin{abstract}
Giant cell arteritis may lead to catastrophic, large-vessel complications from chronic vascular wall inflammation without prompt diagnosis and treatment. We describe a rare case of acute aortic dissection without preceding aneurysm secondary to histologically confirmed giant cell arteritis (GCA) in an 85-year-old female with a four-year history of polymyalgia rheumatica and temporal arteritis diagnosed per biopsy six months prior to presentation. The literature is reviewed and the clinical implications of this case are discussed.
\end{abstract}

\section{Case Report}

An 85-year-old woman with a four-year history of polymyalgia rheumatica and temporal arteritis diagnosed per biopsy six months prior to presentation with an acute sensation of neck tightness with radiation to her bilateral shoulders and the epigastrium. Past medical history was significant for atrial fibrillation status following ablation, coronary artery disease status following remote myocardial infarction medically managed, hyperlipidemia, and hypertension. Her home medications included atenolol, coumadin, and prednisone $20 \mathrm{mg}$ PO twice daily. She had intermittently received several rapidly tapered oral steroid courses over the preceding two years for polymyalgia rheumatica and temporal arteritis flares with resolution of clinical symptoms and normalization of acute inflammatory markers.

At admission, her vital signs and cardiopulmonary exam were within normal limits. An electrocardiogram showed sinus rhythm with first-degree atrioventricular block. Cardiac biomarkers and a chest radiograph were unremarkable. Labs were significant for a stable known normochromic normocytic anemia of chronic disease (hemoglobin $10.3 \mathrm{~g} / \mathrm{dL}$ ), indolent chronic lymphocytic leukemia (white blood cell count of 11,400), an international normalized ratio of 2.0, and an erythrocyte sedimentation rate (ESR) of $49 \mathrm{~mm} / \mathrm{hr}$. A transthoracic echocardiogram eight months prior to admission demonstrated hyperdynamic left ventricular function with ejection fraction of $65 \%-70 \%$, mild aortic insufficiency, and mild concentric left ventricular hypertrophy.

Within several hours of admission, the patient was found to be unresponsive and progressively bradycardic with a depressed left ventricular function with ejection fraction of $45 \%$. She later developed a wide complex tachycardia before terminating in pulseless electrical activity.

Subsequent autopsy showed extensive granulomatous inflammation with lymphocytes, giant cells, and elastic membrane destruction in the aorta and vertebrobasilar and coronary arteries. There was evidence of early aortic root and proximal segment dissection without aneurysmal dilatation, associated with a mild pericardial effusion and a left hemothorax. Despite mild, nonobstructive atherosclerosis, there was no evidence of coronary artery occlusion or myocardial focal ischemic changes. Additionally, no large artery stenosis was appreciated.

\section{Discussion}

Giant cell arteritis (GCA) predominantly affects people of Northern European descent and has an annual incidence of 
20 cases per 100,000 persons aged greater than fifty years $[1,2]$. The risk of developing GCA increases with age with a male-to-female ratio of $1: 2-3$; it is twenty times more common among nonagenarians than those in their fifth or sixth decade $[3,4]$. The average age of patients at time of aortic dissection is 74.5 years (range 58-87 years old) with a similar female predominance of $1: 4$ [3]. In contrast, the typical patient suffering from a non-GCA associated aortic dissection is two to five times more likely to be male, with peak occurrence at 50-66 years old [5]. Improved detection and new imaging modalities have likely contributed to the apparent increase in incidence of large-artery complications over the decades.

The pathogenesis of GCA is unknown [1] but is theorized to be an antigen-driven disease characterized by a granulomatous inflammatory reaction in the adventitia of medium and large arteries [4]. Some genetic polymorphisms, such as HLA-DRB1*-04 alleles, which regulate the expression of cytokines and T cells may contribute to GCA susceptibility $[6,7]$. Activated macrophages and CD4+ T-lymphocytes stimulated by antigen-presenting cells in the vasa vasorum produce inflammatory mediators and reactive oxygen intermediates that disrupt the internal elastic lamina. Resultant neointimal arterial lesions subsequently signal the migration of smooth muscle cells leading to intimal hyperplasia and ultimately ischemic manifestations. It is hypothesized that thoracic involvement of GCA may be more common than abdominal due to its relatively greater vasa vasorum.

There is a wide heterogeneity of large-vessel GCA presentations. Additionally, significant seasonal variations have been observed [8]. The most common clinical features include new onset atypical and severe headache (60\%-90\%), temporal artery tenderness $(40 \%-70 \%)$, fever $(20 \%-50 \%)$, polymyalgia rheumatica $(30 \%-50 \%)$, claudication (jaw, 30$70 \%$ and extremity, $5 \%-15 \%)$, and visual changes (20\%) $[1,2]$. Acute symptomatic aneurysm dissection or clinically apparent aortitis is a presenting feature in $\geq 15 \%$ [1]. However, symptoms may occur late, if any, and are likely underrecognized.

While the most common predisposing factor for aortic dissection is hypertension [4,9], other risk factors may include tobacco smoking and menopausal, hypoestrogenic states that result in asymmetric smooth muscle cell loss [10]. Nuenninghoff et al. identified hyperlipidemia and coronary artery disease as predictors of aortic aneurysm or dissection, although atherosclerosis itself has not been shown to precipitate GCA [14]. Up to $15 \%$ of people with polymyalgia rheumatica will develop giant cell arteritis [11], and conversely, approximately $30 \%-50 \%$ of patients with GCA will have features of PMR [12].

The extent of large artery involvement of GCA is uncertain, but clinically apparent large-vessel disease comprises an estimated $9 \%-14 \%$ of cases [13] with an incidence of aortic aneurysm with or without dissection of approximately 18 per 1000 person-years [14, 15]. Clinically occult GCA has been demonstrated in almost $50 \%$ of patients before aortic dissection $[4,16]$, a complication with an incidence of approximately $2-4$ per 100,000 per year $[17,18]$. In a retrospective cohort study by Nuenninghoff et al. in patients diagnosed with GCA over 50 years, only 9 pts (5\%) developed aortic dissection without preceding aneurysm which was fatal in $77 \%$ of cases [14]. The study by Liu et al. [3] demonstrated that $46 \%$ of patients with histopathology-confirmed giant cell arteritis initially presented with aortic dissection, 85\% of which cases involved the proximal aorta, resulting in an $80 \%$ 2-week mortality rate with fatal pericardial tamponade affecting $50 \%$ of these patients $[9,19]$. This is similar to the $65 \%-75 \%$ mortality rate for untreated aortic dissection, regardless of etiology [20,21].

Compared to the general population, patients with GCA are 17.3 and 2.4 times more likely to develop a thoracic or abdominal aneurysm, respectively [1]. Furthermore, approximately $50 \%$ of those with thoracic aortic aneurysms will die secondary to associated complications [1]. Other largevessel complications include upper extremity stenosis (18\%$21 \%)$ and cerebrovascular ischemic events (7\%). Myocardial infarction from GCA is rarely appreciated [1, 22-24]. These statistics emphasize the dramatic consequences and mortality implications of GCA large-vessel extension for which clinical risk should be assessed early in the disease course.

The American College of Rheumatology diagnostic criteria for GCA include (1) age greater than 50 years, (2) recentonset localized headache, (3) temporal artery tenderness or pulse attenuation, (4) ESR greater than $50 \mathrm{~mm} / \mathrm{h}$, and (5) necrotizing vasculitis on arterial biopsy [25]. At least three positive criteria confer greater than $90 \%$ sensitivity and specificity for GCA. Among older patients with largevessel inflammatory involvement, peripheral pulses should also be carefully evaluated to appreciate new bruits, pulses, and symmetry in blood pressure [1]. However, the diagnostic gold standard is histopathological per arterial wall biopsy that may only be $50-80 \%$ positive based on the clinical pattern of disease [1]. It has been estimated that the median time from diagnosis of GCA to detection of thoracic aortic dissection is $1.1 \mathrm{yrs}$ [14]. Given the potential morbidity of delayed treatment, diagnosis and immediate therapy should be based on high clinical suspicion [26]. Classic laboratory findings include normocytic anemia and reactive thrombocytosis. Albumin may be moderately decreased, and 25\%-35\% of patients will have increased aspartate aminotransferase and alkaline phosphatase elevation, findings that normalize with steroid treatment. The erythrocyte sedimentation rate is often more than $100 \mathrm{~mm} / \mathrm{h}$, though disease activity may better correlate with C-reactive protein (CRP) levels.

Early diagnosis with various imaging modalities may also facilitate prompt treatment to avoid long-term complications. As per guidelines, the initial evaluation of giant cell arteritis should include computed tomographic or magnetic resonance imaging of the thoracic aorta and branch vessels to assess aneurysm or occlusive disease [2]. Alternatively, the 18-fluorodeoxyglucose positron emission tomography (18-FDG PET) has been proposed as both a sensitive and specific diagnostic test that confirms an active vascular process when clinical symptoms and inflammatory markers are ambiguous or equivocal [27, 28]. In patients with confirmed or suspected temporal arteritis or polymyalgia rheumatica (PMA), PET was positive in $76 \%$ of patients with confirmed disease, in $23 \%$ with suspected disease, and 
in $2 \%$ of healthy controls, demonstrating the low rate of false positivity [29]. Suggested screening for aneurysms in patients with GCA includes baseline and annual abdominal ultrasound, chest radiography, and transthoracic echocardiography [28].

Corticosteroids are first-line treatment, and the time elapsed before initiation is an important prognostic factor. Evidence supports a greater than $50 \%$ versus $6 \%$ improvement in vision if therapy is administered within 24 hours from symptom onset [30]. The guidelines recommend high dose corticosteroids, such as prednisone $40-60 \mathrm{mg}$ or its equivalent, for initial treatment, though recent evidence supports similar efficacy with 30 to $40 \mathrm{mg}$ daily dose [2, 31]. Split dosing has not demonstrated increased efficacy, and alternate day treatments have resulted in breakthrough symptoms without decreased risk of osteoporosis [32-34]. Approximately 2-3 months after therapy initiation [2], once the disease is adequately controlled, steroid tapering is appropriate and maintenance therapy may continue for years [35]. At this time, there are no evidence-based recommendations to guide steroid therapy after aortic dissection [4]. Regarding adjunctive therapy, clinical trials have not shown cytotoxic and immunosuppressive agents to be effective steroid-sparing agents $[36,37]$. However, low-dose aspirin is recommended for its 3-4-fold reduction in associated cranial ischemic events as evidenced in retrospective trials $[38,39]$.

Given the risk of steroid-induced osteoporosis, bisphosphonates, calcium, and vitamin $\mathrm{D}$ supplements may also be considered. Although the guidelines do not include specific surgical recommendations for GCA associated thoracic aorta aneurysms and dissection, patients with symptoms suggestive of thoracic aneurysm expansion or rupture should be promptly evaluated for surgical intervention barring limited life expectancy from comorbidities or a substantially impaired quality of life [2].

\section{Conclusion}

This case provides a rare histological example of spontaneous aortic dissection secondary to giant cell arteritis without a preceding aneurysm and supports the hypothesis that inadequate treatment of GCA or PMR may predispose to development of aortic dissection [4, 40]. Aortic complications of GCA can be sudden and catastrophic, occurring years after symptomatic resolution [19]. A normal erythrocyte sedimentation rate (ESR) or C-reactive protein (CRP) in treated patients with PMR or GCA does not exclude the possibility of persistent aortic inflammation and associated risk of large-vessel dissection and rupture. Diagnosis and immediate corticosteroid treatment should be based on high clinical suspicion, and surveillance imaging should follow initial assessment for large-vessel involvement [41]. At this time, surgical treatment of asymptomatic aneurysm and suspected dissection is as per atherosclerotic guidelines [28]. However, further research is indicated regarding the surveillance and treatment of aortic aneurysms and dissections in patients with GCA.

\section{Disclaimer}

The views expressed in this paper are those of the authors and do not reflect the official policy or position of the Department of the Army, Department of Defense, or the U.S. Government.

\section{Conflict of Interests}

The authors have no conflict of interests to disclose. rheumatica and temporal arteritis diagnosed per biopsy six months prior to

\section{References}

[1] A. Villa-Forte and B. Mandell, "Vasculitis," in Braunwald's Heart Diseases: A Textbook of Cardiovascular Medicine, R. Bonow, D. Mann, D. Zipes, P. Libby, and E. Braunwald, Eds., pp. 1878-1879, Elsevier Saunders, Philadelphia, Pa, USA, 2012.

[2] L. F. Hiratzka, G. L. Bakris, J. A. Beckman et al., "2010 ACCF/AHA/AATS/ACR/ASA/SCA/SCAI/SIR/STS/SVM guidelines for the diagnosis and management of patients with thoracic aortic disease: executive summary-a report of the American College of Cardiology Foundation/American Heart Association Task Force on practice guidelines, American Association for Thoracic Surgery, American College of Radiology," Catheterization and Cardiovascular Interventions, vol. 76, no. 2, pp. E43-E86, 2010.

[3] G. Liu, R. Shupak, and B. K. Y. Chiu, "Aortic dissection in giantcell arteritis," Seminars in Arthritis and Rheumatism, vol. 25, no. 3, pp. 160-171, 1995.

[4] B. A. Bengtsson and B. E. Malmvall, "The epidemiology of giant cell arteritis including temporal arteritis and polymyalgia rheumatica. Incidences of different clinical presentations and eye complications," Arthritis and Rheumatism, vol. 24, no. 7, pp. 899-904, 1981.

[5] I. Khan and C. Nair, "Clinical, diagnostic, and management perspectives of aortic dissection," Chest, vol. 122, pp. 311-328, 2002.

[6] J. E. Richardson, D. D. Gladman, A. Fam, and E. C. Keystone, "HLA-DR4 in giant cell arteritis: association with polymyalgia rheumatica syndrome," Arthritis and Rheumatism, vol. 30, no. 11, pp. 1293-1297, 1987.

[7] C. M. Weyand, N. N. H. Hunder, K. C. Hicok, G. G. Hunder, and J. J. Goronzy, "HLA-DRB1 alleles in polymyalgia rheumatica, giant cell arteritis, and rheumatoid arthritis," Arthritis and Rheumatism, vol. 37, no. 4, pp. 514-520, 1994.

[8] E. Nordborg and C. Nordborg, "Giant cell arteritis: epidemiological clues to its pathogenesis and an update on its treatment," Rheumatology, vol. 42, no. 3, pp. 413-421, 2003.

[9] M. F. Berry and Y. J. Woo, "Repair of acute type A aortic dissection associated with temporal arteritis," Annals of Thoracic Surgery, vol. 76, no. 5, pp. 1717-1718, 2003.

[10] P. Duhaut, L. Pinede, S. Demolombe-Rague et al., "Giant cell arteritis and polymyalgia rheumatica: are pregnancies a protective factor? A prospective, multicentre case-control study," Rheumatology, vol. 38, pp. 118-123, 1999.

[11] T. Koga, T. Miyashita, Y. Matsuoka et al., "Acute dissecting thoracic aortic aneurysm in a patient with polymyalgia rheumatica," American Journal of the Medical Sciences, vol. 334, no. 5, pp. 386-388, 2007. 
[12] C. M. Weyand and J. J. Goronzy, "Medium- and large-vessel vasculitis," The New England Journal of Medicine, vol. 349, no. 2, pp. 160-169, 2003.

[13] R. G. Klein, G. G. Hunder, A. W. Stanson, and S. G. Sheps, "Large artery involvement in giant cell (temporal) arteritis," Annals of Internal Medicine, vol. 83, no. 6, pp. 806-812, 1975.

[14] D. M. Nuenninghoff, G. G. Hunder, T. J. H. Christianson, R. L. McClelland, and E. L. Matteson, "Incidence and predictors of large-artery complication (aortic aneurysm, aortic dissection, and/or large-artery stenosis) in patients with giant cell arteritis: a population-based study over 50 years," Arthritis and Rheumatism, vol. 48, no. 12, pp. 3522-3531, 2003.

[15] M. A. Gonzalez-Gay, C. Garcia-Porrua, A. Piñeiro, R. PegoReigosa, J. Llorca, and G. G. Hunder, "Aortic aneurysm and dissection in patients with biopsy-proven giant cell arteritis from northwestern Spain: a population-based study," Medicine, vol. 83, no. 6, pp. 335-341, 2004.

[16] I. Marie, A. Proux, P. Duhaut et al., "Long-term follow-up of aortic involvement in giant cell arteritis: a series of 48 patients," Medicine, vol. 88, no. 3, pp. 182-192, 2009.

[17] L. K. Bickerstaff, P. C. Pairolero, L. H. Hollier et al., "Thoracic aortic aneurysms: a population-based study," Surgery, vol. 92, no. 6, pp. 1103-1108, 1982.

[18] T. Giujusa, C. Dario, G. Risica et al., "Aortic dissection: an incidence study based on hospital cases," Cardiologia, vol. 39, no. 2, pp. 107-112, 1994.

[19] J. M. Evans, C. A. Bowles, J. Bjornsson, C. J. Mullany, and G. G. Hunder, "Thoracic aortic aneurysm and rupture in giant cell arteritis: a descriptive study of 41 cases," Arthritis and Rheumatism, vol. 37, no. 10, pp. 1539-1547, 1994.

[20] A. Hurst, V. Johns, and S. Kime, "Dissecting aneurysm of the aorta: a review of 505 cases," Medicine, vol. 37, pp. 217-219, 1958.

[21] D. Miller, "Surgical management of aortic dissections: indications, perioperative management and long term results," in Aortic Dissection, R. M. Doroghazi and E. E. Slater, Eds., pp. 193-243, New York, NY, USA, 1983.

[22] B. Karger and G. Fechner, "Sudden death due to giant cell coronary arteritis," International Journal of Legal Medicine, vol. 120, no. 6, pp. 377-379, 2006.

[23] J. Save-Soderbergh, B. E. Malmvall, R. Andersson, and B. A. Bengtsson, "Giant cell arteritis as a cause of death. Report of nine cases," Journal of the American Medical Association, vol. 255, no. 4, pp. 493-496, 1986.

[24] M. Wenger and J. Schneider, "Sudden cardiac death in giant cell arteritis," Vasa, vol. 25, no. 4, pp. 373-377, 1996.

[25] G. Hunder, D. Bloch, B. Michel et al., "The American College of Rheumatology 1990 criteria for the classification of giant cell arteritis," Arthritis and Rheumatism, vol. 33, pp. 1122-1128, 1990.

[26] C. Bosson, J. Hadrami, G. Kharsa, D. Q. Lim, M. Nitel, and Y. Chotard, "Spontaneous rupture of the ascending aorta disclosing inflammatory arteritis," Archives des Maladies du Coeur et des Vaisseaux, vol. 89, no. 12, pp. 1683-1686, 1996.

[27] S. P. Janssen, E. H. Comans, A. E. Voskuyl, W. Wisselink, and Y. M. Smulders, "Giant cell arteritis: heterogeneity in clinical presentation and imaging results," Journal of Vascular Surgery, vol. 48, no. 4, pp. 1025-1031, 2008.

[28] P. Houthuizen, P. E. Polak, M. A. L. Edelbroek, and C. H. Peels, "Giant cell arteritis as a cardiovascular entity," Netherlands Heart Journal, vol. 17, no. 7-8, pp. 281-283, 2009.

[29] D. Blockmans, S. Stroobants, A. Maes, and L. Mortelmans, "Positron emission tomography in giant cell arteritis and polymyalgia rheumatica: evidence for inflammation of the aortic arch," American Journal of Medicine, vol. 108, no. 3, pp. 246-249, 2000.

[30] M. Gonzalez-Gay, R. Blanco, V. Rodriguez-Valverde et al., "Permanent visual loss and cerebrovascular accidents in giant cell arteritis: predictors and response to treatment," Arthritis and Rheumatism, vol. 41, pp. 1497-1504, 1998.

[31] G. Nesher, A. Rubinow, and M. Sonnenblick, "Efficacy and adverse effects of different corticosteroid dose regimens in temporal arteritis: a retrospective study," Clinical and Experimental Rheumatology, vol. 15, no. 3, pp. 303-306, 1997.

[32] G. Hunder, S. Sheps, G. Allen, and J. Joice, "Daily and alternateday corticosteroid regimens in treatment of giant cell arteritis: comparison in a prospective study," Annals of Internal Medicine, vol. 82, pp. 613-618, 1975.

[33] V. Kyle and B. L. Hazleman, "Treatment of polymyalgia rheumatica and giant cell arteritis. II. Relation between steroid dose and steroid associated side effects," Annals of the Rheumatic Diseases, vol. 48, no. 8, pp. 662-666, 1989.

[34] P. Ruegsegger, T. C. Medici, and M. Anliker, "Corticosteroidinduced bone loss. A longitudinal study of alternate day therapy in patients with bronchial asthma using quantitative computed tomography," European Journal of Clinical Pharmacology, vol. 25, no. 5, pp. 615-620, 1983.

[35] L. Fernandez-Herligy, "Duration of corticosteroid therapy in giant cell arteritis," The Journal of Rheumatology, vol. 7, no. 3, pp. 361-364, 1980.

[36] G. S. Hoffman, M. C. Cid, K. E. Rendt-Zagar et al., "Infliximab for maintenance of glucocorticosteroid-induced remission of giant cell arteritis a randomized trial," Annals of Internal Medicine, vol. 146, no. 9, pp. 621-630, 2007.

[37] G. S. Hoffman, M. C. Cid, D. B. Hellmann et al., "A multicenter, randomized, double-blind, placebo-controlled trial of adjuvant methotrexate treatment for giant cell arteritis," Arthritis and Rheumatism, vol. 46, no. 5, pp. 1309-1318, 2002.

[38] G. Nesher, Y. Berkun, M. Mates et al., "Low-dose aspirin and prevention of cranial ischemic complications in GCA," Arthritis and Rheumatism, vol. 50, no. 4, pp. 1332-1337, 2004.

[39] M. S. Lee, S. D. Smith, A. Galor, and G. S. Hoffman, "Antiplatelet and anticoagulant therapy in patients with giant cell arteritis," Arthritis and Rheumatism, vol. 54, no. 10, pp. 3306-3309, 2006.

[40] C. Agard, T. Ponge, G. Fradet et al., "Giant cell arteritis presenting with aortic dissection: two cases and review of the literature," Scandinavian Journal of Rheumatology, vol. 35, no. 3, pp. 233-236, 2006.

[41] F. Martínez-Valle, R. Solans-Laqué, J. Bosch-Gil, and M. Vilardell-Tarrés, "Aortic involvement in giant cell arteritis," Autoimmunity Reviews, vol. 9, no. 7, pp. 521-524, 2010. 


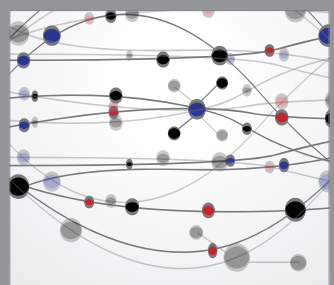

The Scientific World Journal
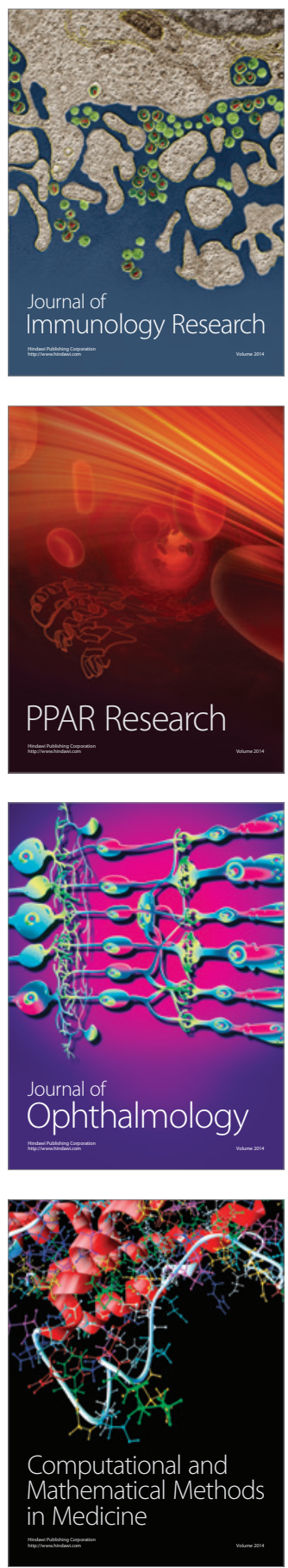

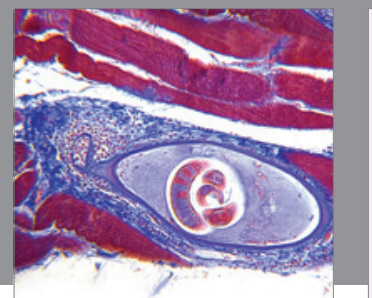

Gastroenterology

Research and Practice
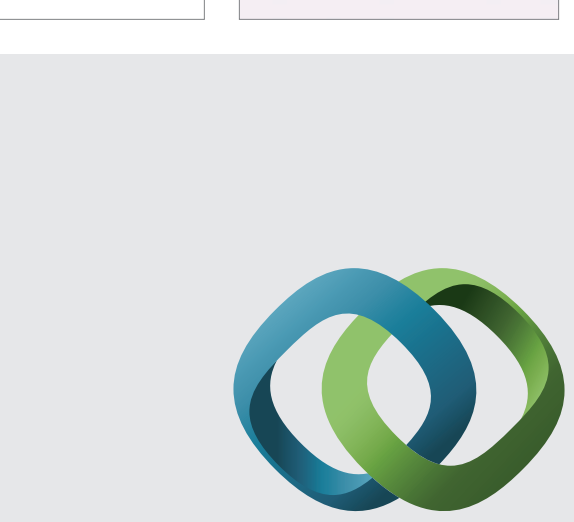

\section{Hindawi}

Submit your manuscripts at

http://www.hindawi.com
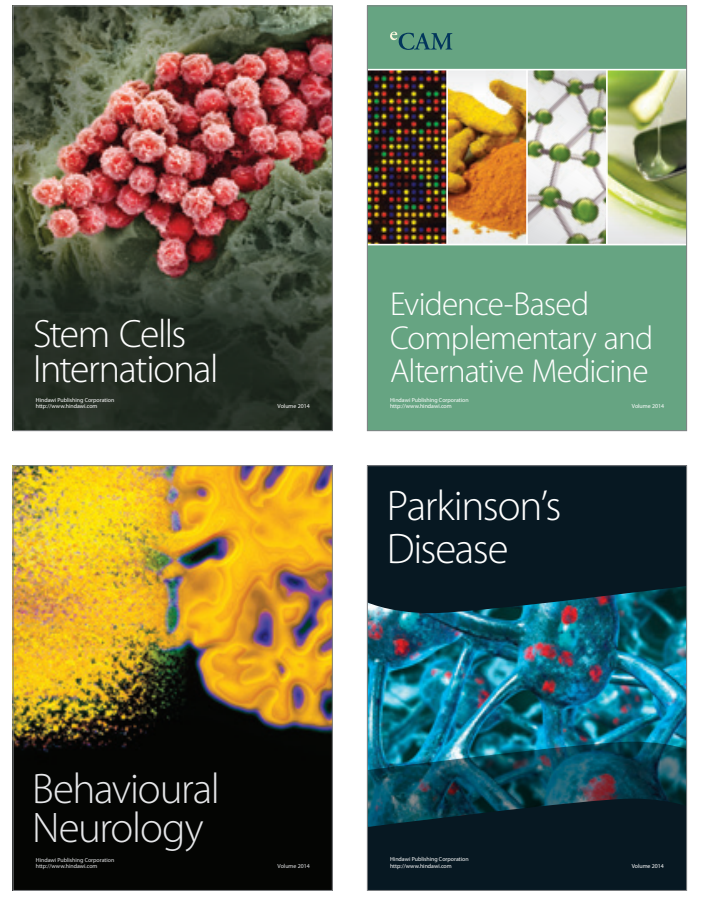
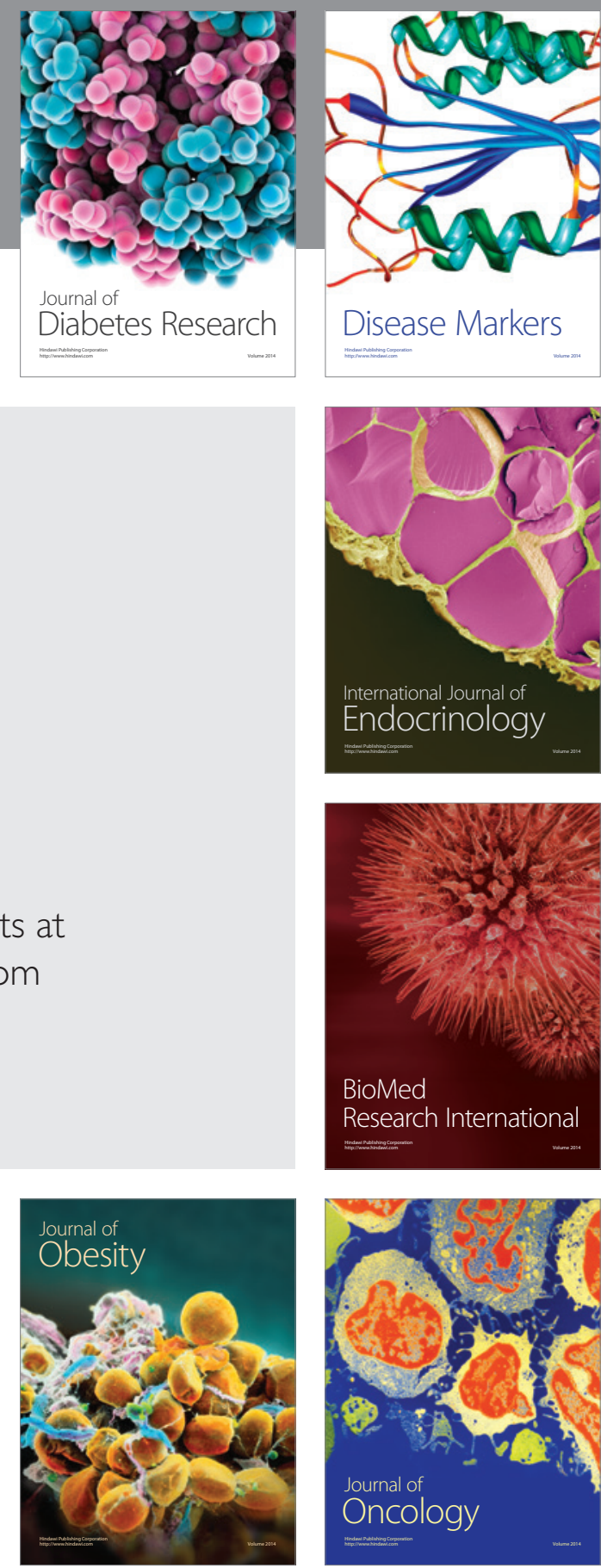

Disease Markers
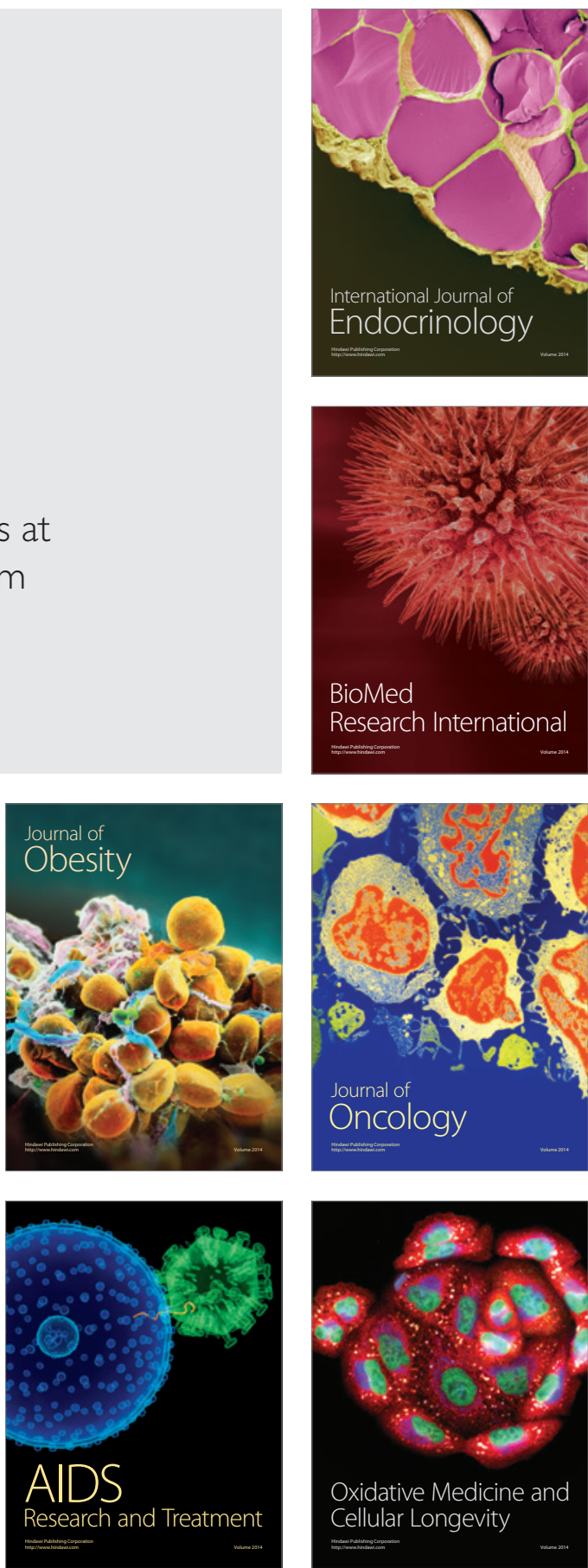